\title{
Simulation Study of Steam Assisted Gravity Drainage (SAGD) in Fractured Systems
}

\author{
S. Mobeen Fatemi \\ Department of Chemical \& Petroleum Engineering, Sharif University of Technology, Tehran - Iran \\ e-mail: mobeen.fatemi@gmail.com
}

\begin{abstract}
Résumé - Étude de simulation du drainage gravitaire assisté par injection de vapeur dans les systèmes fracturés - Le drainage gravitaire assisté par injection de vapeur (Steam Assisted Gravity Drainage, SAGD), procédé de récupération améliorée du pétrole (Enhanced Oil Recovery, EOR) mis au point pour la production assistée du pétrole et de bitume, est étudié de manière théorique et de manière expérimentale avec des modèles et dans des réservoirs conventionnels et se révèle être une méthode d'EOR prometteuse dans certains réservoirs d'huile lourde. Dans le présent travail, des études par simulation du SAGD ont été réalisées sur différents modèles fracturés, les fractures se trouvant à la fois dans la zone voisine du puits et dans la zone au-dessus du puits, et même en présence de réseaux de fractures. À un stade précoce du processus de SAGD dans un système fracturé, la vapeur se déplace d'abord à travers les fractures, puis les blocs de la matrice sont chauffés principalement par conduction et éventuellement par une certaine pénétration de la vapeur. L'interface huile-vapeur se forme et se développe à partir de tous les côtés de la matrice et de la chambre de vapeur et non par formation et rétrécissement d'une chambre de vapeur au centre de chaque bloc. La récupération par SAGD augmente en présence de fractures verticales mais elle est gênée par les fractures horizontales. L'espacement des fractures n'est pas un paramètre très important dans la mise en ouvre des procédés par vapeur dans les modèles fracturés. Une fréquence de fracture élevée améliore les résultats par SAGD en réduisant la durée nécessaire pour le chauffage du bloc de matrice et en améliorant le processus de chauffage par conduction. L'effet des fractures horizontales entre les puits d'injection et les puits de production est insignifiant dans la mesure où le mécanisme de réalisation de SAGD dépend de la formation d'une chambre de vapeur dans la zone au-dessus du puits plutôt que dans la zone voisine du puits. Une augmentation de l'extension des fractures horizontales réduit la récupération finale de pétrole qui peut être obtenue par SAGD. Dans le modèle de réseau de fractures, la présence de fractures verticales améliore la récupération par rapport à ce qui est obtenu dans le cas de fractures horizontales seules.
\end{abstract}

\footnotetext{
Abstract - Simulation Study of Steam Assisted Gravity Drainage (SAGD) in Fractured Systems The Steam Assisted Gravity Drainage (SAGD) process, a developed Enhanced Oil Recovery (EOR) process to recover oil and bitumen, has been studied theoretically and experimentally in conventional reservoirs and models and is found a promising EOR method for certain heavy oil reservoirs. In this work simulation studies of the SAGD process were made on different fractured models consisting of fractures in both Near Well Region (NWR) and Above Well Region (AWR) and even in the presence of networked fractures. At early stage of the SAGD process in fractured system, steam moves through the fractures first and then the matrix blocks are heated primarily by conduction and possibly some steam invasion. The steam-oil interface forms and develops from all sides of the matrix and oil chamber rather than a steam chamber forms and shrinks in the center of each block. SAGD process recovery enhanced
} 
in the presence of vertical fractures but horizontal fractures were harmful on the recovery. Fracture spacing was not a very important parameter in the performance of steam processes in fractured models. High fracture frequency improved SAGD performance since it reduced the time period necessary for heating the matrix block and enhanced heating process by conduction. Horizontal fractures between injector-producer wells had an insignificant effect on the process since SAGD production mechanism is based on steam chamber development in AWR rather than NWR. Horizontal fractures extension increase reduced ultimate oil recovery attainable by $S A G D$. In the networked fracture model the presence of vertical fractures improved the recovery achieved in the case of horizontal fractures alone.

\section{INTRODUCTION}

\subsection{Introduction to SAGD Process}

The recovery of heavy crudes uses a special form of steam flooding that has become known as steam-assisted gravity drainage (SAGD) [1,2].

SAGD was developed by Butler for the in situ recovery of the Alberta bitumen. The process relies on the gravity segregation of steam, utilizing a pair of parallel horizontal wells, maximizing the use of gravity forces, placed $5 \mathrm{~m}$ apart (in the case of tar sands) in the same vertical plane $[2,3]$.

The top well is the steam injector, and the bottom well serves as the producer. Steam rises to the top of the formation, forming a steam chamber. High reduction in viscosity mobilizes the bitumen, which drains down by gravity and is captured by the producer placed near the bottom of the reservoir. Continuous injection of steam causes the steam chamber to expand and spread laterally in the reservoir. High vertical permeability is crucial for the success of SAGD. The process performs better with bitumen and oils with low mobility, which is essential for the formation of a steam chamber, and not steam channels [1]. SAGD has been more effective in Alberta than in California and Venezuela for the same reason [4].

In SAGD process the movement of oil to the production well is caused by gravity forces, and the geometry is such that the oil moves approximately parallel to the interface that forms the boundary of a growing, steam-saturated zone known as the steam chamber [1].

In the ideal SAGD process, a growing steam chamber forms around the horizontal injector and steam flows continuously to the perimeter of the chamber where it condenses and heats the surrounding oil. Effective initial heating of the cold oil is important for the formation of the steam chamber in gravity drainage processes [5].

The intention in developing the steam-assisted gravity drainage process was to devise a means whereby heavy oil or bitumen could be removed in a systematic manner in order to give a more complete recovery than is possible in conventional steam flooding processes, where the oil is moved by pushing it with injected fluids [1].
Gravity is already present throughout the reservoir, and by using it as the chief driving force to effect oil movement, it is possible to avoid the differential fingering that occurs when viscous oils are moved by pushing with a less viscous fluid [1].

It was reasoned that if steam were injected above but close to a production well that was completed at the base of the reservoir, the steam would tend to rise and the condensates, together with warmed oil, would fall. The oil and condensate would be removed continuously from the production well. It was thought that if these liquids were not removed too quickly, then the tendency of the steam to flow directly to the production well and thus to bypass the reservoir could be reduced or possibly even eliminated. This is analogous to the ability of a steam trap to allow the flow of condensate from the bottom of a steam-heated radiator without allowing significant bypassing of the steam [1].

An attraction of this concept is that, although the injection well and the production well can be very close, the mechanism will cause the steam chamber to expand gradually and eventually allow drainage from a very large area. The injector and producer do not have to span the drainage area. Another advantage is that the heated oil remains hot as it flows towards the production well. In conventional steam flooding, the oil that is displaced from the steam chamber is cooled and is hard to push to the production well. In SAGD the oil remains heated as it flows around the steam chamber [1].

\subsection{SAGD Simulation Literature Review}

There are some attempts in the literature to simulate the SAGD process and to understand better the sensitivity of the process to various operational parameters.

Kamath et al. [6] developed a two-dimensional numerical model of the steam assisted gravity drainage process with a pair of horizontal wells (SAGD) for heterogeneous layered tar sand reservoirs applied to Ugnu reservoir to study the effect of heterogeneity on the growth of steam chamber and the process performance. The effect of various reservoir parameters such as porosity, permeability, initial mobile water saturation, Dykstra-Parson's permeability variation, reservoir anisotropy and shale barriers on the SAGD process performance was 
investigated. The SAGD Performance improves significantly with high steam injectivities, low mobile water saturation near the producer, absence of continuous shale barriers, high vertical to horizontal permeability ratio and optimum injector-producer vertical spacing. The lateral well spacing affects the oil production in the earlier period and the project life [6].

Later Kisman and Yeung [7] developed a similar study with a two-dimensional numerical model which considers the relative effects of permeability, relative permeability, wettability changes, oil viscosity, thermal conductivity, flow barriers and solution gas [7].

Elliot and Kovscek [8] simulated a single-well SAGD (SW-SAGD) and performed a sensitivity analysis to improve the process performance at early times. The sensitivity analysis performed indicates that SW-SAGD is most applicable to heavy oils with initial viscosity below $10 \mathrm{~Pa}-\mathrm{s}$ $(10000 \mathrm{cP})$. Additionally, the reservoir must be sufficiently thick to allow significant vertical steam chamber growth. The sensitivity analysis also indicates that the presence of relatively small amounts of solution gas aids the recovery process by enhancing volumetric expansion of the oil on heating. They concluded that cyclic steam injection was the most efficient pre-heating method for SW-SAGD [8].

Akin and Bagci [9] made an experimental investigation and optimization of startup procedure for single-well steamassisted gravity drainage. They compared two methods of continuous and cyclic steam injection and concluded that cyclic steam injection yields better results for SW-SAGD. They simulated the process with CMG (STARS). Their numerical model warmed more slowly than the experiment and a good match was not achieved.

Barillas et al. [10] determined the optimum steam injection rate for a homogenous reservoir whose sole heterogeneity was barriers using CMG (STARS). They noted that vertical permeability has a significant role on oil recovery. Parameters like horizontal permeability and viscosity have negligible effect on optimum steam injection rate. They investigated the effect of reservoir thickness too [10].

The SAGD simulation appeared successful on conventional unfractured reservoirs. However a few studies have been done on simulation in fractured formation despite the fact that there are 20 known large carbonate reservoirs containing heavy oil and bitumen throughout the world spread over a dozen of countries and at various depths, temperatures and API's [11].

Bagci [12] made experimental and simulation studies on 3-D SAGD process in both homogeneous and fractured reservoirs. The shape and growth of the steam chamber in a fractured pack are different from those observed in the uniform permeability pack without fracture. An elongated steam chamber is observed for fractured case while the homogeneous model had almost round steam chamber. Good results were obtained for the history matching of the experimental data. The author also investigated the effects of fracture orientation and different well configurations. He concluded that the horizontal well pair scheme gave higher recovery of original oil in place as expected. Existing or induced vertical fractures could be used to improve initial oil production rates. The fractures were successful in shortening the time to generate near breakthrough condition between the two wells. They also enhanced expansion rate of steam chamber area. However, higher steam-oil ratios were observed in both vertical and horizontal fractures than in the conventional homogeneous model [12].

Chen et al. [13] investigated the effects of heterogeneity on SAGD performance. The heterogeneity includes the effect of a hydraulic fracture either vertical or horizontal. For the case with a vertical fracture, the main oil production period starts shortly after steam injection and exhibits a much greater average oil rate, more than twice the oil rates of the horizontal fracture and the base case without fracture. The observed different effects of horizontal and vertical fractures are explained by examining how the steam chamber profile is affected by the presence of fractures [13].

Das [14] investigated the feasibility of thermal processes such as SAGD and CSS (Cyclic Steam Stimulation) in fractured carbonated formation. Sensitivity of the process to fracture frequency, oil viscosity, oil saturation, wettability, imbibition (i.e, Capillary pressure), matrix permeability and relative permeability relations have been investigated too. Among these parameters the oil viscosity and wettability played the most significant role. Different fracture spacings show approximately similar cumulative recoveries. Surprisingly more steam went into the system with wider fracture spacing probably due to invasion and drainage from the matrix. They suggested further examination is needed [14].

\section{METHOdOLOGY}

\subsection{Simulation of SAGD in Conventional Model: Description of the Model}

In order to simulate the SAGD process, a rectangular model was considered. The simulator used in this study was Computer Modeling Group's (CMG), Steam and Thermal Advance Reservoir Simulator (STARS) version 2004. Phase behavior data, as well as equation of state (EOS) phase envelope was made by the Winprop module of CMG.

This simulator has been successfully applied to the SAGD process by other investigators such as Akin and Bagci [9], Barillas et al. [10] and Bagci [12], in conjunction with their experimental data.

The model dimensions in this study were set to $3.28 \mathrm{ft}$ $(100 \mathrm{~cm})$ by $3.28 \mathrm{ft}(100 \mathrm{~cm})$ by $0.1 \mathrm{ft}(0.3048 \mathrm{~cm})$. The 


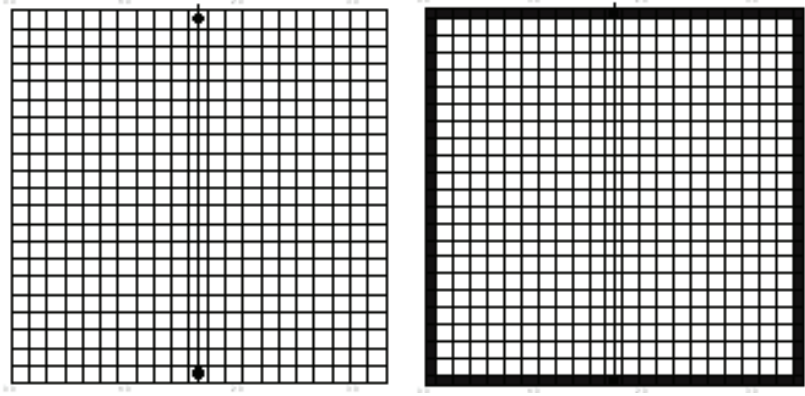

Figure 1

Schematic representation of conventional (left) and fractured (right) models.

average porosity and permeability were set to $30 \%$ and $10 \mathrm{md}$, respectively. The irreducible water saturation was set to 0.2 ; also, 0.15 residual oil saturation is assigned to the model. One injector is located at top center of the model and one producer is located right below it at the bottom of the model (Fig. 1).

The system pressure and temperature were set at 75 psia and $51^{\circ} \mathrm{C}$, respectively. The crude oil used in simulations is synthetic oil composed of three pseudocomponents known as Light Oil (LO), Medium Oil (MO) and Heavy Oil (HO), so the simulation process is a compositional type treatment of oil and gas phases. From this three pseudocomponents only LO and MO have been considered as volatile oil since their equilibrium constants have been identified, and $\mathrm{HO}$ was taken as a dead oil. The Peng-Robinson Equation of State (PREOS) [17] was used in the simulations to verify synthetic oil type according to its Pressure-Temperature phase diagram. The lumped oil system used in the simulations is shown in Table 1. Also, the model parameters are summarized in Table 2.

\subsection{Simulation of SAGD Process in Fractured Models}

In a non-conventional fractured reservoir two types of reservoirs may be distinguished: fractured reservoirs of single porosity; and fractured reservoirs of double porosity. Both reservoirs are made of a network of fractures surrounding blocks. In the case of dual porosity system, two overlapping continuums, one corresponding to the medium of the fractures and one corresponding to the medium of blocks, are considered. Also, two values of properties and permeabilities are attributed to each point, e.g. fracture porosity and block porosity. In addition, there is no matrix-matrix communication in a dual-porosity model [18].

In this work, a double porosity model is constructed and used as fracture system. It was assumed that a very thin high
TABLE 1

The lumped oil system in the simulation

\begin{tabular}{|c|c|c|}
\hline \multicolumn{2}{|c|}{ Component } & \multirow{2}{*}{$\frac{\text { Composition (mole fraction }}{0.1614}$} \\
\hline LO & $(\mathrm{MW}=250)$ & \\
\hline MO & $(\mathrm{MW}=450)$ & 0.2356 \\
\hline $\mathrm{HO}$ & $(\mathrm{MW}=600)$ & 0.6030 \\
\hline
\end{tabular}

TABLE 2

Data for initializing the conventional model

\begin{tabular}{l|l}
\hline Parameters & Values \\
\hline Length in $X, Y, Z$-direction & $100 \mathrm{~cm} \times 100 \mathrm{~cm} \times 0.3048 \mathrm{~cm}$ \\
\hline Porosity & 0.3 \\
\hline Permeability & $10 \mathrm{md}$ \\
\hline Number of pseudocomponents & $3(\mathrm{LO}, \mathrm{MO}, \mathrm{HO})$ \\
\hline Temperature & $51^{\circ} \mathrm{C}$ \\
\hline Initial pressure & $517107 \mathrm{~Pa}$ \\
\hline Initial water saturation & 0.2 \\
\hline Residual oil saturation & 0.15 \\
\hline Number of injection/producer wells & $1 / 1$ \\
\hline Steam quality & 0.7 \\
\hline
\end{tabular}

TABLE 3

Data for initializing the fractured model

\begin{tabular}{c|c}
\hline Grid type & Cartesian \\
\hline Fracture porosity & 1.00 \\
\hline Fracture permeability & $10000 \mathrm{md}$ \\
\hline
\end{tabular}

permeable layer surrounds the rectangular model considered in the previous section. Figure 1 shows the cross section of the fractured model. The black lines surrounding the model are simulated fractures. Producer and injector are placed the same as conventional model presented in the same figure. As can be seen in this figure, this model is based on developing the dual porosity model by using the single porosity pattern to view the performance of the process in the single block model more clearly. Properties of the fracture should be assigned to the fracture layer. For example, the fracture permeability should be much larger than the matrix permeability. Also, fracture porosity should have a reasonable value, which is different with that of matrix porosity. The porosity of those grids representing the fracture was taken as 1.00. The other sensitive parameter was relative permeability curve for the fractures that should form two straight lines crossing each other at the center [19].

The matrix dimensions, system pressure and temperature and oil sample were set similar to what we had in the simulation of the conventional reservoir. One injection well was 
located at the top centre of the model in the fracture layer and one production well at the bottom fracture layer exactly below the injection. The steam injection system was identical to that used in the previous section. The fractured-model parameters other than those indicated in Table 2 are summarized in Table 3.

\subsection{Results and Discussions}

\subsubsection{Simulation of the SAGD Process in Conventional Model}

Figure 2 shows the saturation profiles for oil after 4 hours production. It is clear from these figures that the development and progress of the steam front in conventional model follows the same pattern observed in laboratory studies as reported by previous researchers (e.g. Butler [1, 2]). According to Figure 2, the steam diffuses into the matrix and reduces heavy oil viscosity by conduction and the steam chamber develops laterally and vertically.

\subsubsection{Simulation of the SAGD Process in Fractured Model}

The steam flows immediately after injection through the fracture system (see Fig. 1) that has higher permeability than the matrix block, and goes to the end of the fracture part in both sides. Then, the steam heats the matrix and diffuses upward into the matrix, because of the lower density compared to the reservoir oil and attempts to fill the space above the oil, so the interface is gradually developed in both sides and the heavy oil is accumulated at the centre of the model (Fig. 2).

Also, the mobilized layer of the oil drains by its gravity to the production well. As the time passes, the steam diffuses into the matrix from the side fractures, because the side fractures are now filled with the steam and the oil chamber develops as shown in Figure 2. Figure 2 reveals a very important difference between the SAGD processes in conventional compare to fractured system. In conventional reservoirs, the steam flows only through the injector into matrix; thus, the steam front grows around the injector and the oil bank surrounds the steam bank. On the other hand, in the fractured system, due to differences in matrix and fracture permeabilities, the steam first spreads through the fractures and then starts heating up and diffusing into matrix from all parts of the matrix. Thus, the steam surrounds the oil bank, and an oil chamber rather than steam chamber is formed and shrinks as the process proceeds. Similar recovery mechanisms have been developed for other EOR processes (like VAPEX (vapor extraction) and ISC (in situ combustion)) applied to NFR [20-22]. This mechanism improves the recovery process in fractured model compare to the conventional case (Fig. 3). For further study on fractures orientation effect, different patterns used which have been shown in Figure 4. In this figure black bold dots show injector (upper one) and

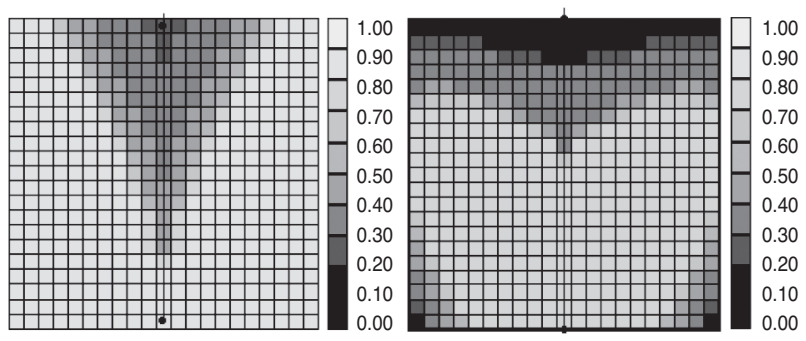

Figure 2

Oil saturation in conventional (left) and fractured (right) models after 4 months.

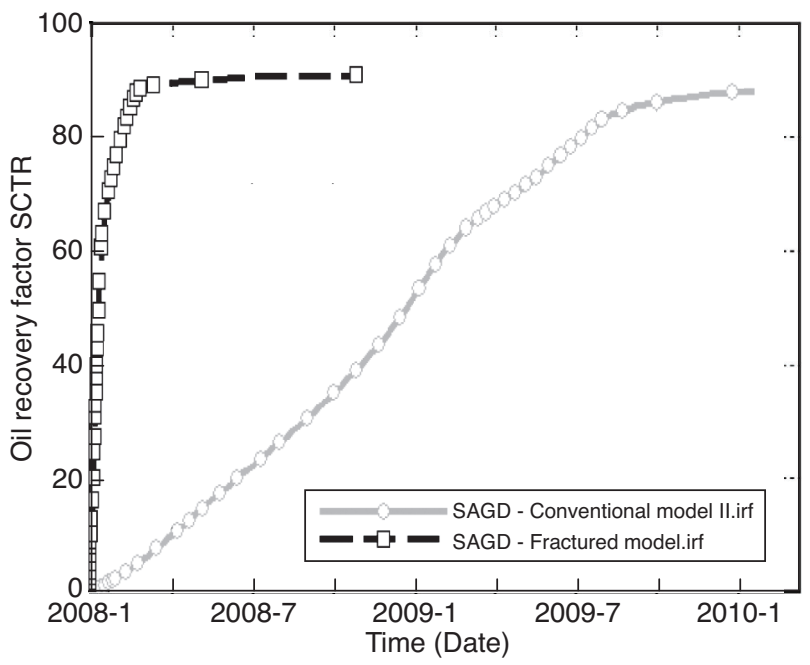

Figure 3

Oil recovery comparison for conventional and fractured models (see Fig. 1).

producer (lower one) and the simulated fractures have been magnified by gray and black strips in the systems. Injector is located at the lower layers of models in Figure 4 compare to top location in Figure 1, to simulate the countercurrent recovery mechanism in SAGD.

\subsubsection{Simulation of the Effect of Vertical Fractures}

To study the effect of vertical fractures, patterns A and D have been used. Vertical fractures caused rapid vertical extension of both temperature front and oil depleted area (Fig. 5). This may be partially has been caused by the presence of high conductivity areas of fractures which provide as a suitable continuum for steam to reach into the farther areas of the reservoir. In addition to this, there will be chance for steam to diffuse and affect a matrix from more contact area which now is available appreciating fractures, rather than one-side propagation in conventional model. In such a 


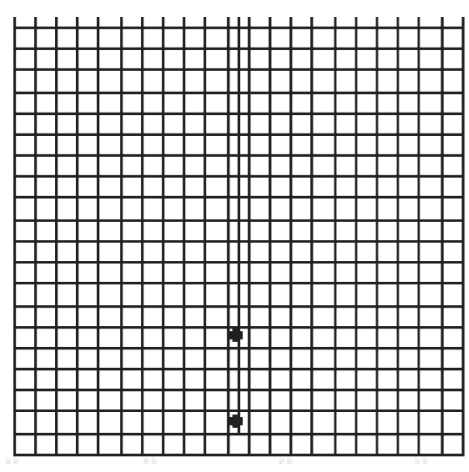

A

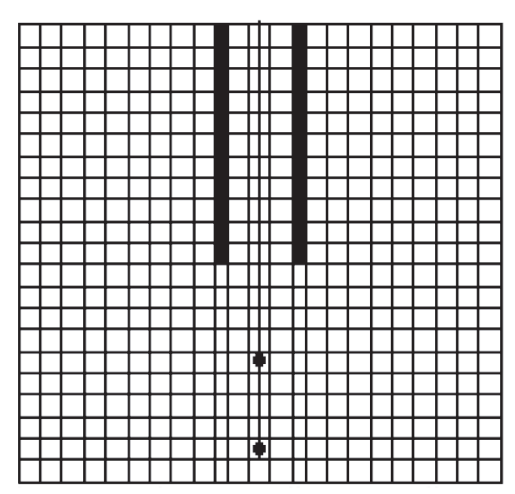

D

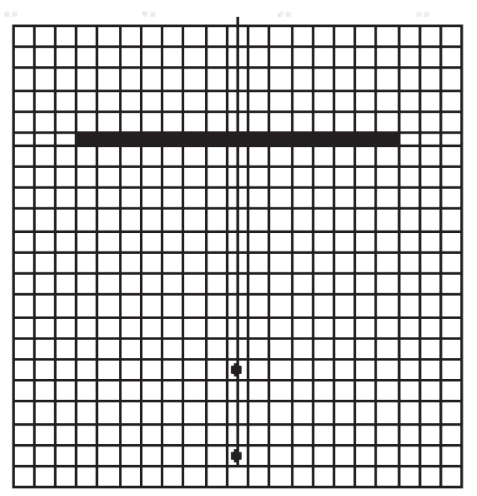

G

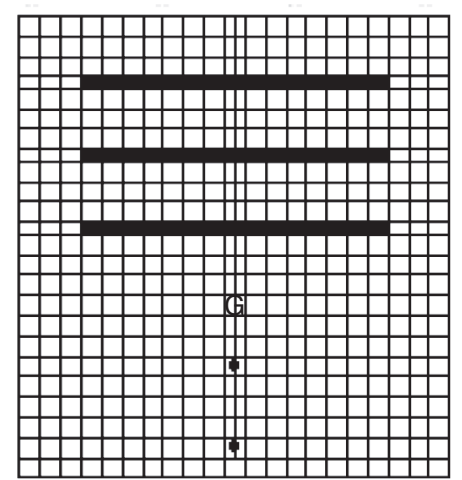

J

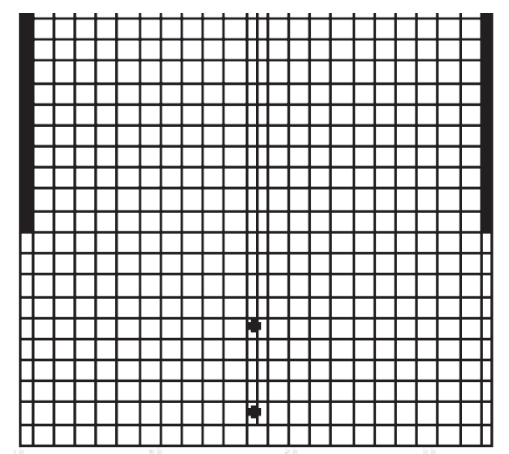

B

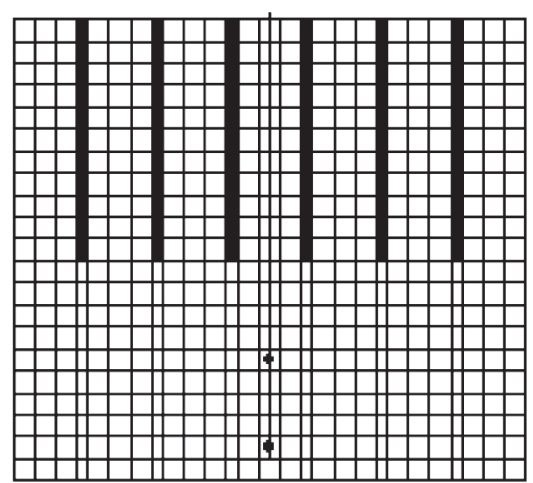

E

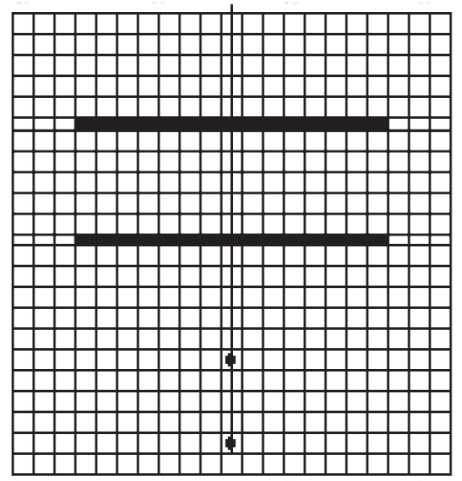

$\mathrm{H}$

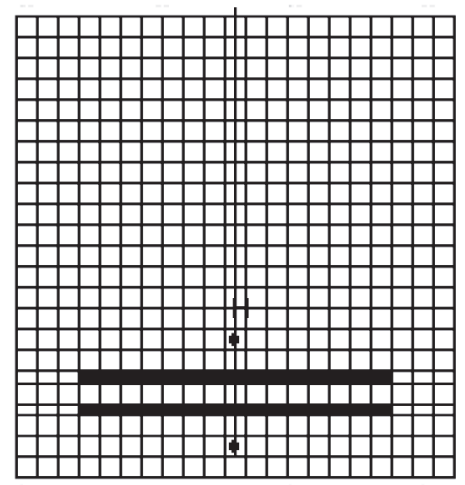

$\mathrm{K}$

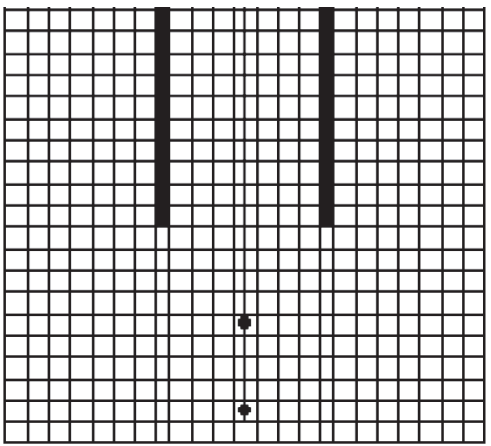

C

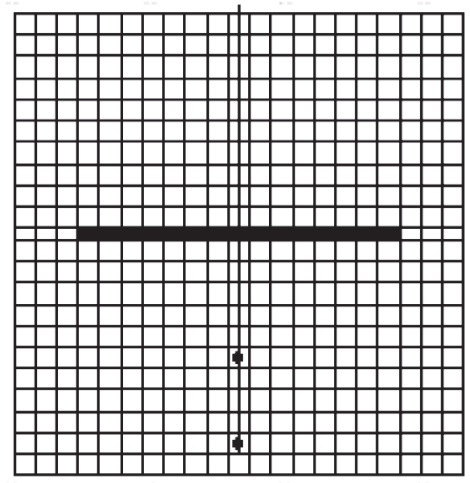

$\mathrm{F}$

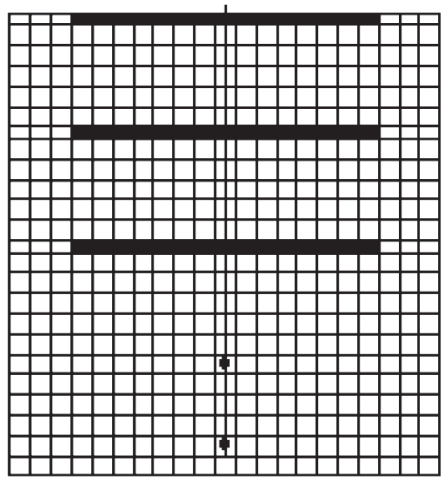

।

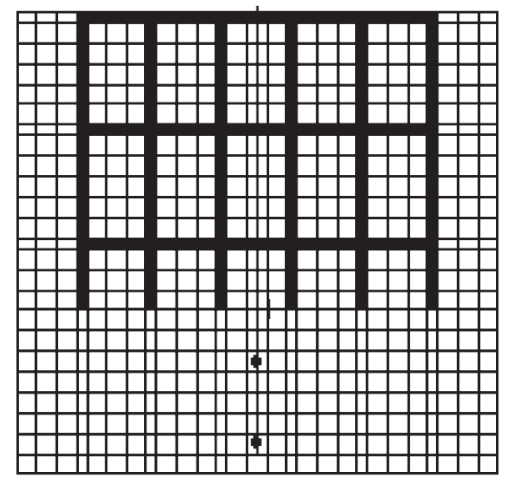

L

Figure 4

Different fractured model to study the effect of fracture geometrical properties. 

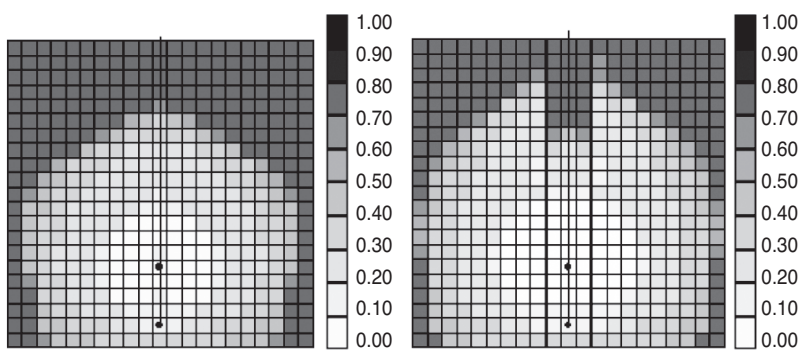

Figure 5

Oil saturation profile in A (left) and D (right) patterns after 10 months.

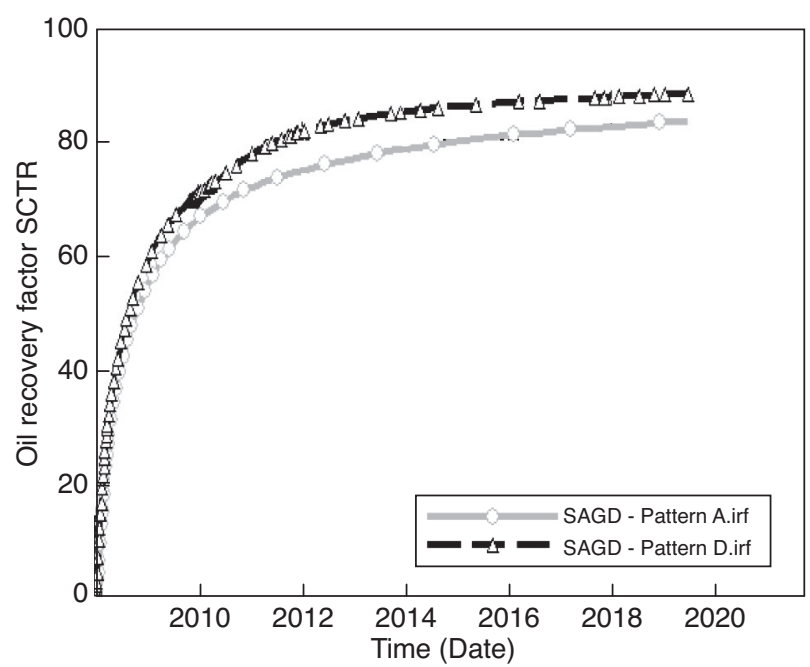

Figure 6

Effect of vertical fractures on oil recovery vs. time.

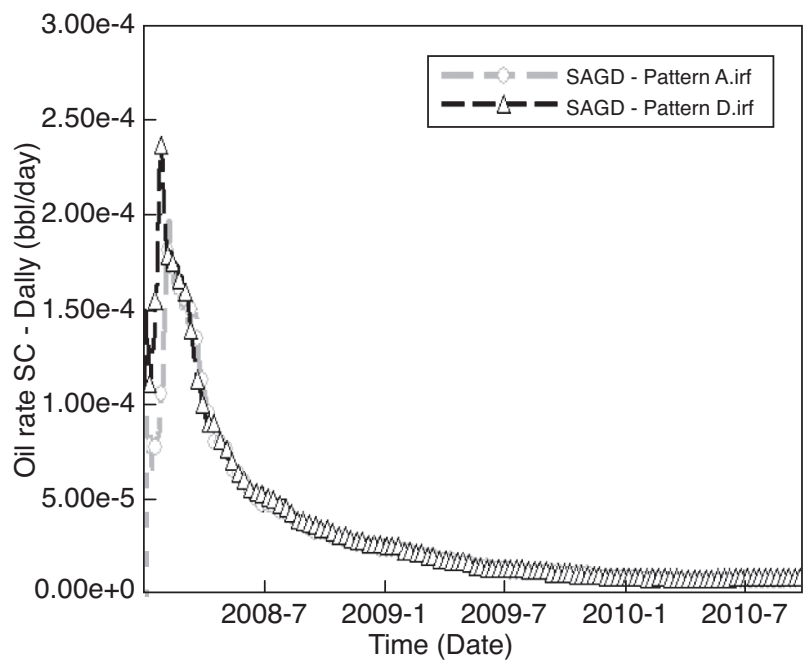

Figure 7

Effect of vertical fractures on oil production rate. case ultimate oil recovery factor increases compare to conventional model (see Fig. 6 and Fig. 7).

\subsubsection{Simulation of the Effect of Vertical Fractures Spacing}

To study the effect of vertical fractures spacing patterns B, C and $\mathrm{D}$ have been used. All models increased ultimate oil recovery compare to conventional model (Fig. 8). But simulations results showed that for a specified operating and reservoir characteristics (except fracture spacing) there is an optimum vertical fracture spacing that in which the ultimate oil recovery is maxima for a known number of vertical fractures. As a matter of fact, this phenomenon is caused by the restricted ability of injected steam to heat up (conduction phenomena) and diffuse into a specified volume of matrix, optimistically.

\subsubsection{Simulation of the Effect of Vertical Fractures Density}

To study the effect of fractures density, patterns D and E have been used. Higher vertical fracture density, increased upward (vertical) expansion of steam chamber (Fig. 9), provided lower resistive media for steam to flow, and delivered higher contact area heating the matrix by conduction. These phenomenons improve the ultimate oil recovery significantly (Fig. 10).

\subsubsection{Simulation of the Effect of Horizontal Fractures}

To study the effect of horizontal fractures patterns A and F have been used. The same as vertical fractures, horizontal fractures also provide as low flow resistivity mediums in the model. But the effect is lateral expansion of the steam

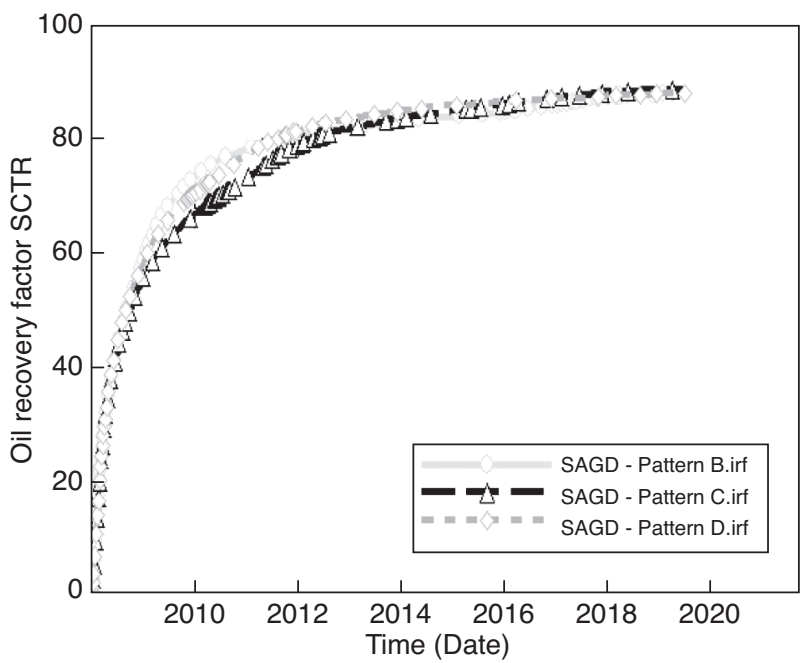

Figure 8

Vertical fractures density effect on oil recovery factor. 


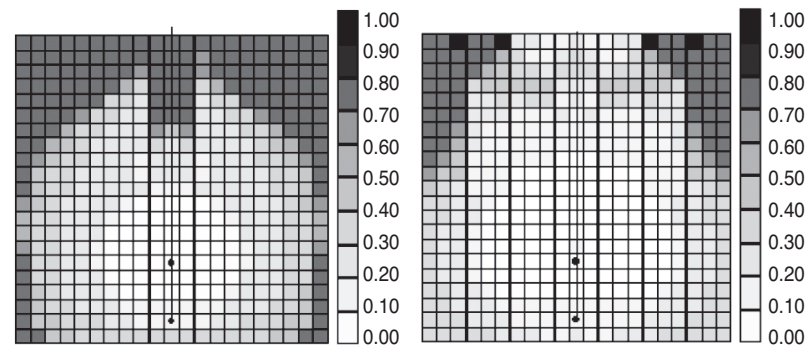

Figure 9

Oil saturation profile in pattern D (left) and pattern E (right) after 10 months.

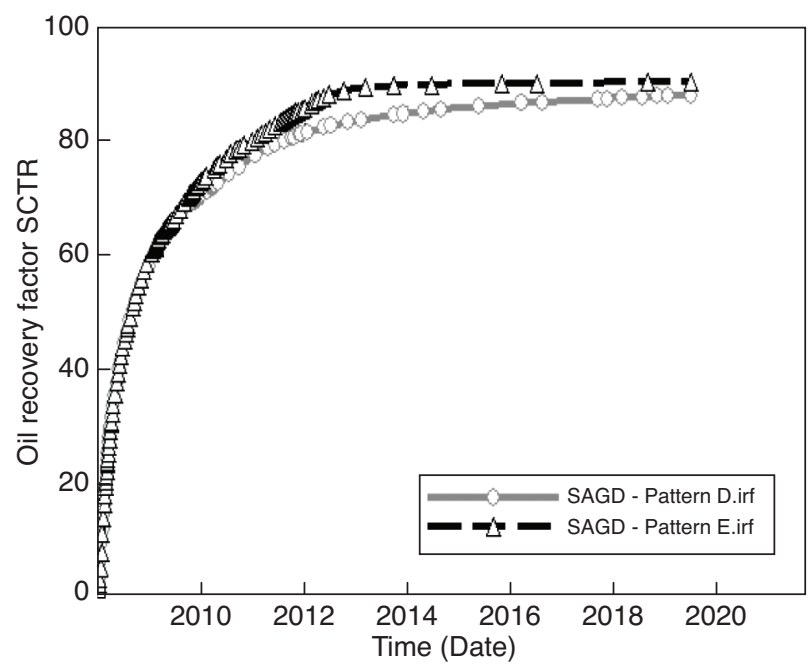

Figure 10

Vertical fractures density effect on oil recovery $v s$. time.

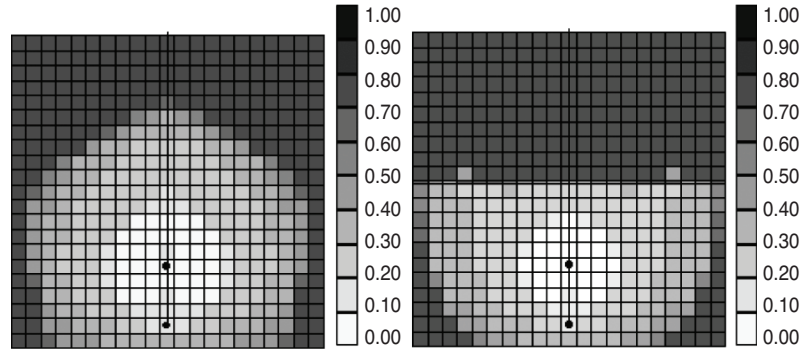

Figure 11

Oil saturation profiles in patterns A (left) and pattern $\mathrm{F}$ (right) after 10 months.

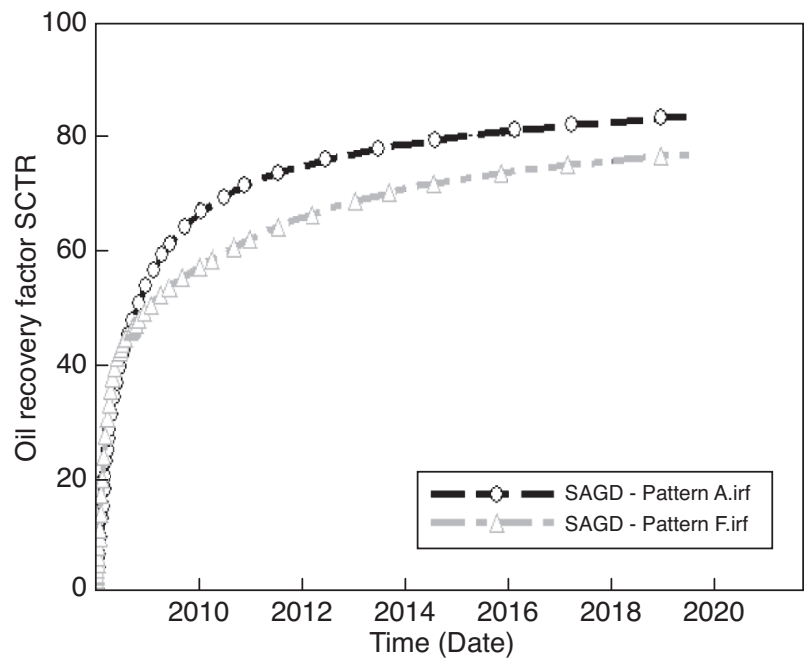

Figure 12

Effect of horizontal fracture on oil recovery $v s$. time. chamber (Fig. 11). In such a case lateral expansion of the steam chamber will be significant compare to conventional reservoirs since there is a small fraction of injected steam that can diffuse according to the molecular diffusion mechanism from fracture into the upper located matrix, the ultimate oil recovery achievable by SAGD process will be reduced significantly (Fig. 12).

\subsubsection{Simulation of the Effect of First Horizontal Fracture Location}

To study this effect patterns $\mathrm{F}$ and $\mathrm{G}$ have been used. In the case of longer vertical distance between injection well and horizontal fracture, there will be more part of reservoir achievable by steam and less part of it will be restricted from steam by the horizontal fracture (Fig. 13). This causes that the oil recovery be somewhat higher at initial times for $\mathrm{G}$ pattern compare to F (Fig. 14). But after while oil recovery will be lower in $\mathrm{G}$ and even the ultimate oil recovery is less.
As a matter of fact in this case the most affecting parameter for the steam reach to the after fracture matrix is diffusion and there is less effect of injection pressure which pushes steam to the next matrix in $\mathrm{F}$ pattern.

\subsubsection{Simulation of the Effect of Horizontal Fractures Density}

Patterns F, H and I have been used. Higher horizontal fractures density will reduce the ultimate oil recovery further (Fig. 15) since the steam chamber development will be more restricted by the consequent set of horizontal fractures. Each horizontal fracture provides a high permeable media in the traversal direction of steam chamber development and hydrocarbons drainage. This will prohibit steam from dispersion into the matrix media and restricts the steam chamber development by low rate steam molecular diffusion from matrix to fracture and vice versa. The same is true for the warmed oil which should be drain from upper layers to the lower 


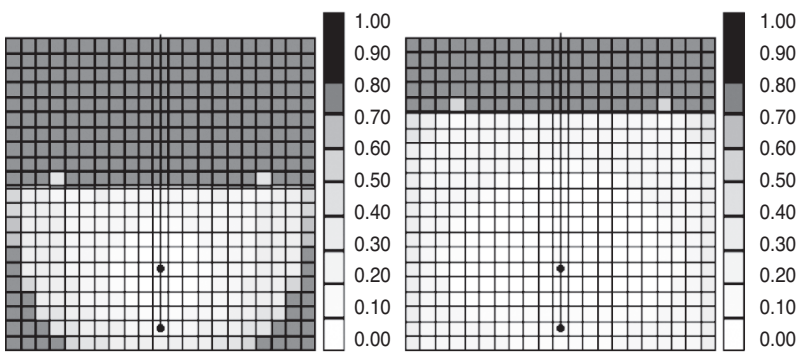

Figure 13

Oil saturation in patterns F (left) and G (right), after 10 months.

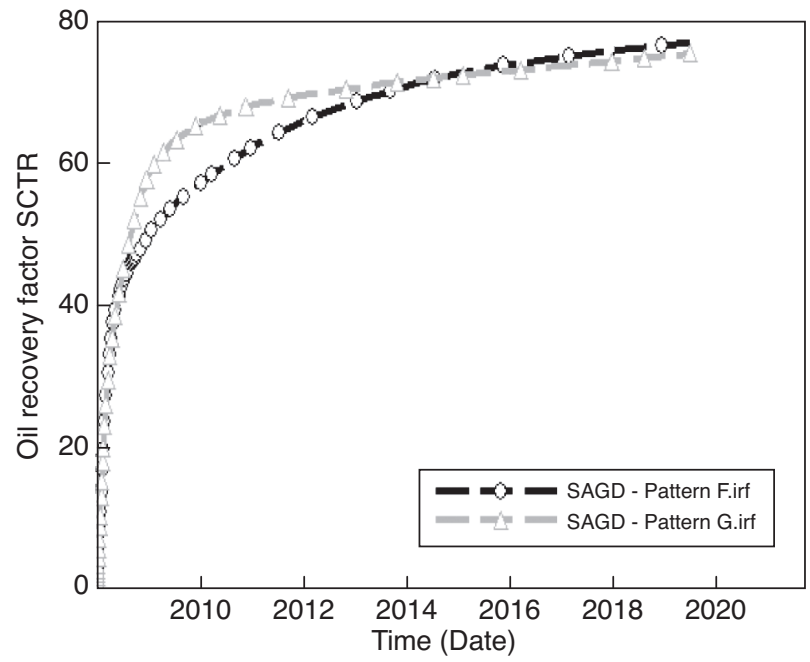

Figure 14

Effect of horizontal fracture location on oil recovery.

producer. These phenomenons in conjunction together reduce the final oil recovery achievable in the case of higher horizontal fracture density.

\subsubsection{Simulation of the Effect of Horizontal Fractures Spacing}

Patterns I and J have been used. Reduction of horizontal fracture spacing distance (in the case of similar location of the first horizontal fracture respect to injector) will reduce the ultimate oil recovery (Fig. 16), since the chance of steam chamber development will restrict by consequent horizontal fractures.

\subsubsection{Simulation of the Effect of Horizontal Fracture between Two Wells}

SAGD process recovery mechanism is based on countercurrent oil gravity drainage from outer boundary of the developed steam chamber (above injector parts).
According to its special production mechanism, horizontal fracture between two wells (pattern $\mathrm{K}$ ) has minimum effect on the oil recovery. These fractures have no disastrous effect on ultimate oil recovery like AWR (Above Well Region) horizontal fractures since they don't restrict the steam chamber development as the steam will spread upwards according to its lower density compare to heavy oil. From another point of view the warmed oil from upper parts will drain to these horizontal fractures, and will directly flow toward low pressure area around producing well through these low flow resistivity mediums. From there the drainage medium in rock porous media into the

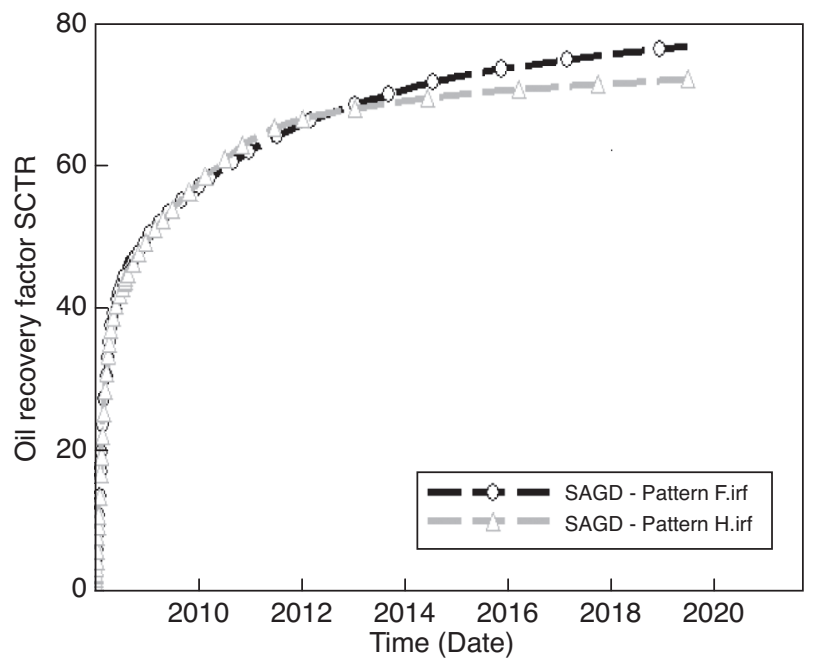

Figure 15

Effect of horizontal fractures density on oil recovery.

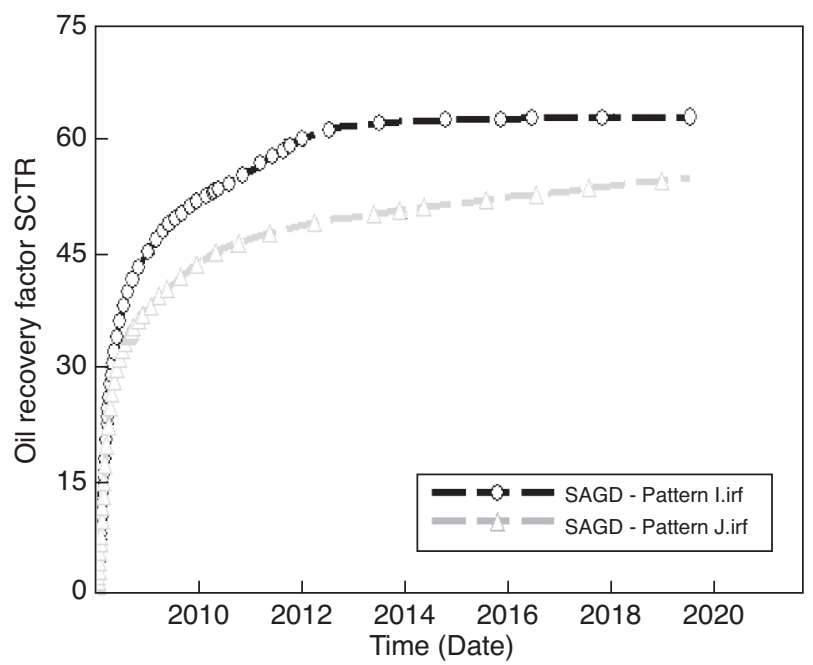

Figure 16

Effect of horizontal fractures spacing on oil recovery $v s$. time. 


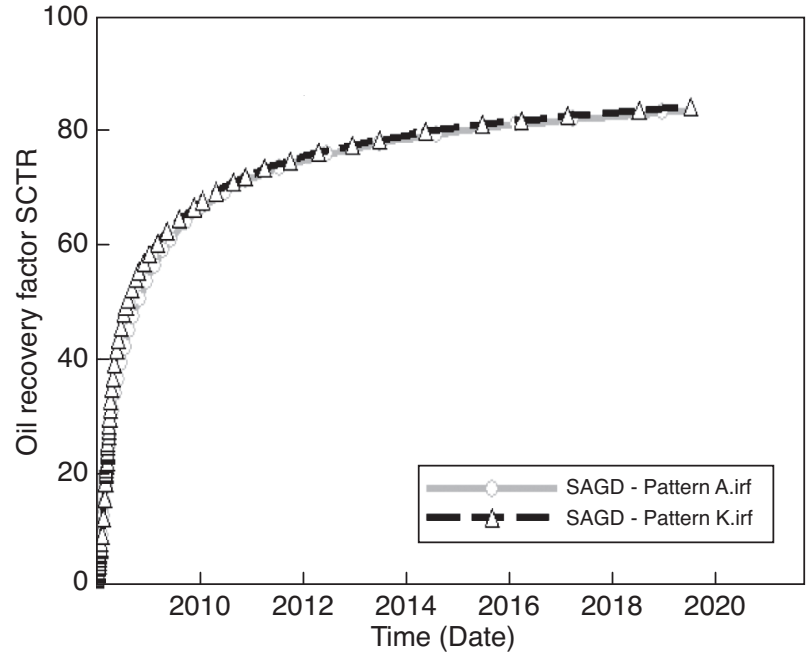

Figure 17

NWR horizontal fractures effect on oil recovery $v s$. time.

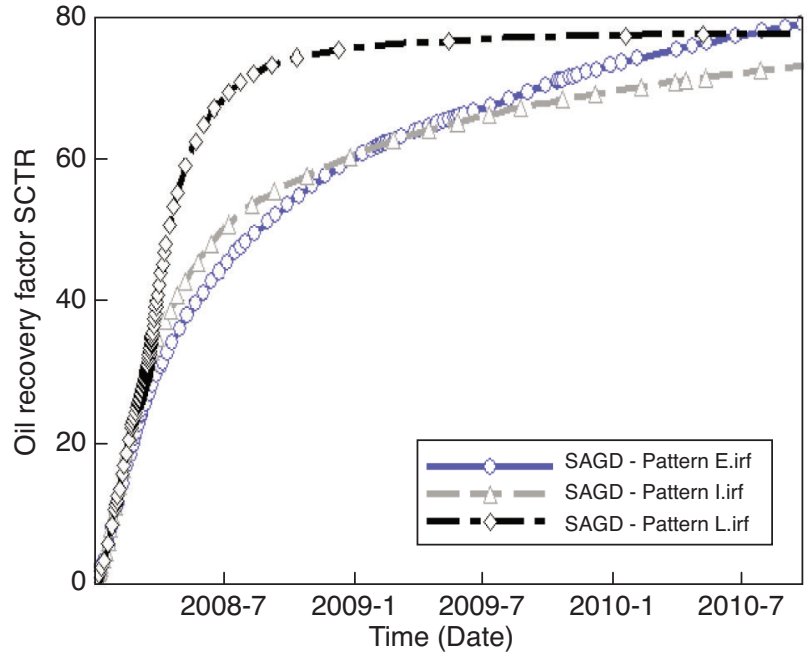

Figure 18

Effect of networked fractures on oil recovery vs. time. producer is less than conventional outer boundary of developed steam chamber. This special recovery mechanism will slightly enhance oil recovery in the case of NWR (Near Well Region) horizontal fractures compare to nonfractured model (Fig. 17).

\subsubsection{Simulation of the Effect of Networked Fractures}

To study the effect of horizontal and vertical fractures on SAGD performance in NFR (Naturally Fractured Reservoirs) simultaneously, networked fractures should be developed on the model. There are two well-known models to simulate networked fractures: The Warren and Root Model [23] and The De-Swaan-O Model [24]. In the first one the fractures form a continuous and uniform network oriented in such a way as to be parallel to the principal directions permeability. The fractures are assumed to be of constant width. In the case of an isotropic network or a variation in a given direction, the anisotropy must be simulated. The fracture spacing associated to fracture density is directly related to the fracture permeability and porosity. The De Swaan-O (1976) model is similar to the WarrenRoot (1963) model, but instead of matrix blocks shaped as parallelepipeds, the block units are shaped as spheres superimposed in a regular orthogonal distribution. The fracture volume is represented by the spherical interspaced which is further correlated with porosity values. In this paper the Warren-Root (1963) model has been used (pattern L). Simulation results showed that vertical fractures enhanced SAGD recovery achievable from NFR compared to the case that only horizontal fractures exist (Fig. 18).
TABLE 4

Ultimate oil recovery factor in the case of each pattern

\begin{tabular}{c|c|c|c}
\hline Pattern & Oil Recovery & Pattern & Oil Recovery \\
\hline A & $82 \%$ & G & $75 \%$ \\
\hline B & $85 \%$ & H & $77 \%$ \\
\hline C & $87 \%$ & I & $63 \%$ \\
\hline D & $89 \%$ & J & $55 \%$ \\
\hline E & $92 \%$ & K & $83 \%$ \\
\hline F & $78 \%$ & L & $79 \%$ \\
\hline
\end{tabular}

\section{CONCLUSIONS}

SAGD oil recovery mechanism is different in fractured models and conventional ones, since in the single block fractured model oil chamber rather than steam chamber develops. Vertical fractures improve oil recovery compare to the disastrous effect of horizontal fractures. Vertical fractures density increase, improves SAGD oil recovery but horizontal fractures density increase restricts steam chamber development in reservoir. Near injection well horizontal fractures have less effect on recovery than far ones. In networked fractures, vertical fractures improve recovery achievable by horizontal fractures.

\section{REFERENCES}

1 Butler R.M. (1991) Thermal Recovery of Oil and Bitumen, Prentice-Hall, New Jersey.

2 Butler R.M. (1998) SAGD Comes of AGE, J. Can. Petrol. Technol. 37, 7, 9-12. 
3 Elliot K.T., Kovscek A.R. (1999) A Numerical Analysis of Single-Well Steam Assisted Gravity Drainage Process (SWSAGD), 20th Annual Workshop and Symposium on Enhanced Oil Recovery International Energy Agency.

4 Butler R.M. (1985) A new approach to the modeling of steamassisted gravity drainage, J. Can. Petrol. Technol. 24, 3, 42-51.

5 Thomas S. (2008) Enhanced Oil Recovery - An Overview, Oil Gas Sci. Technol.-Rev. IFP 63, 1, 9-19

6 Kamath V.A., Sinha Sandeep, Hatzignatiou D.G. (1993) Simulation Study of Steam-Assisted Gravity Drainage Process in Ugnu Tar Sand Reservoir, SPE paper 26075.

7 Kisman K.E., Yeung K.C. (1995) Numerical Study of SAGD Process in the Burnt Lake Oil Sands Lease, SPE paper 30276.

8 Elliot K.T., Kovscek A.R. (1999) A Numerical Analysis of Single-Well Steam Assisted Gravity Drainage Process (SWSAGD), 20th Annual Workshop and Symposium on Enhanced Oil Recovery International Energy Agency.

9 Akin S., Bagci S.A. (2001) Laboratory study of single-well steam-assisted gravity drainage process, J. Petrol. Sci. Eng. 32, 23-33.

10 Barillas J.L.M., Dutra Jr. T.V., Mata W. (2006) Reservoir and operational parameters influence in SAGD process, J. Petrol. Sci. Eng. 54, 1-2, 34-42.

11 Chen Q., Gerritsen M.G., Kovscek A.R. (2007) Effects of Reservoir Heterogeneities on the Steam-Assisted Gravity Drainage Process, SPE paper 109873.

12 Bagci A.S. (2006) Experimental and Simulation Studies of SAGD Process in Fractured Reservoirs, presented at $S P E / D O E$ Symposium on Improved Oil Recovery, Tulsa, Oklahoma, SPE paper 99920.

13 Chen Q., Gerritsen M.G., Kovscek A.R. (2007) Effects of Reservoir Heterogeneities on the Steam-Assisted Gravity Drainage Process, SPE paper 109873.
14 Das S. (2007) Application of Thermal Recovery Processes in Heavy Oil Carbonate Reservoirs, SPE paper 105392.

15 STARS User's Guide (2004) Computer Modeling Group.

16 Winprop User's Guide (2004) Computer Modeling Group.

17 Peng D.Y., Robinson D.B. (1976) A New Two-constant Equation of State, Ind. Eng. Chem. Fund. 15, 59-64.

18 Golf-Racht T.D. Van (1982) Fundamentals of Fractured Reservoir Engineering, 1st ed., Elsevier.

19 Aguilera R. (1995) Naturally Fractured Reservoirs, 2nd ed., Penn Well Books.

20 Rostami B., Azin R., Kharrat R. (2009) Investigation of the VAPEX Process in High-Pressure Fractured Heavy-Oil Reservoirs, presented at SPE International Thermal Operations and Heavy Oil Symposium, Calgary, Alberta, Canada, SPE Paper 97766.

21 Azin R., Kharrat R., Ghotbi C., Vossoughi S. (2005) Applicability of the VAPEX Process to Iranian Heavy Oil Reservoirs, Presented at the 14th SPE Middle East Oil and Gas Show and Conf., Bahrain, SPE 92720.

22 Fatemi S.M., Kharrat R., Vossoughi S. (2008) Feasibility Study of In-Situ Combustion (ISC) in 2D Laboratory Scale Fractured Systems Using a Thermal Reservoir Simulator, presented at World Heavy Oil Congress (WHOC), Edmonton, Canada, Paper 2008-449.

23 Warren J.E., Root P.J. (1963) The behavior of naturally fractured reservoirs, SPE Journal, September, pp. 245-255.

24 Saidi A.M. (1987) Reservoir Engineering of Fractured Reservoirs (Fundamental and Practical aspects), Copyright by TOTAL Edition Press, ISBN: 2-905 143-09-6.

Final manuscript received in November 2008 Published online in August 2009 work owned by others than IFP must be honored. Abstracting with credit is permitted. To copy otherwise, to republish, to post on servers, or to redistribute to lists, requires prior specific permission and/or a fee: Request permission from Documentation, Institut français du pétrole, fax. +33147527078 , or revueogst@ifp.fr. 